\title{
Genetic Determinants of Paget's Disease of Bone
}

\author{
Navnit S. Makaram ${ }^{1} \cdot$ Stuart H. Ralston ${ }^{1}$ (i) \\ Accepted: 17 March 2021 / Published online: 14 May 2021 \\ (C) The Author(s) 2021
}

\begin{abstract}
Purpose of Review To provide an overview of the role of genes and loci that predispose to Paget's disease of bone and related disorders.

Recent Findings Studies over the past ten years have seen major advances in knowledge on the role of genetic factors in Paget's disease of bone (PDB). Genome wide association studies have identified six loci that predispose to the disease whereas family based studies have identified a further eight genes that cause PDB. This brings the total number of genes and loci implicated in PDB to fourteen. Emerging evidence has shown that a number of these genes also predispose to multisystem proteinopathy syndromes where PDB is accompanied by neurodegeneration and myopathy due to the accumulation of abnormal protein aggregates, emphasising the importance of defects in autophagy in the pathogenesis of PDB.

Summary Genetic factors play a key role in the pathogenesis of PDB and the studies in this area have identified several genes previously not suspected to play a role in bone metabolism. Genetic testing coupled to targeted therapeutic intervention is being explored as a way of halting disease progression and improving outcome before irreversible skeletal damage has occurred.
\end{abstract}

Keywords Paget's disease of bone $\cdot$ genetics $\cdot$ osteoclast $\cdot$ SQSTM1 $\cdot$ multisystem proteinopathy

\section{Introduction}

Paget's disease of bone (PDB) is a common skeletal disorder, characterised by focal regions of abnormal and disorganised bone remodelling at one (monostotic) or more (polyostotic) sites. The disease mainly involves the axial skeleton, such that the pelvis $(70 \%)$, femur $(55 \%)$, lumbar spine $(53 \%)$, skull $(42 \%)$, and tibia $(32 \%)$ are preferentially affected. Clinically, the disease result in symptoms of bone pain, deformity, and pathological fracture. Osteoarthritis related to bone deformity and subchondral sclerosis is a common consequence and frequently requires arthroplasty [1]. Patients with PDB also have an increased risk of developing osteosarcoma, and although rare $(0.3 \%$ of PDB patients), virtually all osteosarcomas that occur in adulthood do so in patients with PDB [2]. Similarly, some families have been described in which PDB is accompanied by giant cell tumours [3].

This article is part of the Topical Collection on Genetics

Stuart H. Ralston

stuart.ralston@ed.ac.uk

1 Centre for Genomic and Experimental Medicine, Institute of Genetics and Cancer, University of Edinburgh, Edinburgh EH4 2XU, UK

\section{Epidemiology}

Paget's disease of bone (PDB) is estimated to affect about $2 \%$ of the UK population over 55 years of age, with a greater incidence in men (1.4:1) [2]. There is marked geographical variation in the occurrence of PDB. The UK has the highest incidence of PDB in the world, but the disease is also common in other European countries such as Spain, Italy, and France. It is also common in people of European descent, and because of this, the incidence is high in countries that have historically been common destinations for migration of these communities, such as Australia, Canada, New Zealand, South Africa, and the USA $[4,5]$. In contrast, PDB is rare in the Indian subcontinent, Scandinavia, China, and the Far East [6].

The incidence of PDB increases markedly with age; it is rare below the age of 50 years, but doubles each decade thereafter affect about $7.6 \%$ of men and $5.4 \%$ of women by the eighth decade in the UK [7]. The striking geographic variation in PDB and correlation with trends in the migration of certain population cohorts has emphasised the importance of genetic factors in the pathogenesis of PDB. Environmental factors also play a significant role however, reflected by the reduced incidence and severity of PDB in several locations including the UK, continental Europe, and 
New Zealand $[2,8,9]$, but no significant change in other regions such as Italy and the USA [10-12]. The identity of environmental triggers for PDB is unclear [13]. Full discussion of this area is beyond the scope of this article, but suggested environmental influences include low dietary calcium intake [14], vitamin D deficiency [15], excessive biomechanical loading [16], tobacco use [17], wood heating during childhood [18], lead exposure [19, 20], air pollution [21], contact with animals [22], and a slow virus infection with one of the paramyxoviruses [23, 24].

\section{Inheritance of Paget's Disease}

Familial clustering is common in classical PDB, and in some families the disease is inherited in an autosomal dominant manner. In the UK, a family history of PDB is obtained in around $15 \%$ of PDB cases but in other regions such as Quebec, a positive family history is obtained in up to $50 \%$ of individuals [25]. It has been estimated that penetrance reaches $80-90 \%$ by the seventh decade in people who carry mutations in SQSTM1 which is the most important predisposing gene for PDB [26-28] (see below). The relative risk of developing PDB in relatives of an affected individual is approximately seven times greater than in relatives of controls, and this rises to 20 times for relatives of patients with severe or early-onset disease [29]. Traditionally PDB is characterised into familial or sporadic subtypes, based on the presence of a positive family history, but it is important to remember that as the disease may be asymptomatic, family history may be more common than one thinks.

A number of rare syndromes have been identified in which clinical, radiological, or histological features in common with PDB are observed but where there is an early age at onset and the diseases are inherited in a Mendelian manner. The clinical and pathophysiological features of these disorders have recently been reviewed elsewhere [30 ${ }^{\circ}$, but the genes responsible will also be discussed here.

A significant observation from recent findings has been the relatively large effect sizes of the loci influencing the development of PDB compared with other common diseases of the musculoskeletal system, such as osteoporosis and rheumatoid arthritis $[31 \bullet \cdot$. This indicates that susceptibility to PDB is likely to be mediated by the inheritance of a relatively small number of genes with large effect sizes as opposed to a large number of genes with small effect sizes. For example, a number of common variants have been identified within or close to genes such as CSF1, TNFRSF11A, TM7SF4, NUP205, and RIN3 which individually are not sufficient to cause the disease but which act cumulatively to significantly increase the risk of developing PDB.

\section{Candidate Genes for Paget's Disease}

Several genes and loci that predispose to familial PDB have been identified over the last two decades by a combination of linkage analysis in families and genome wide association studies (GWAS) in unrelated individuals. Many of the PDBassociated genes have important roles in osteoclast differentiation and function as illustrated in Fig. 1.

\section{Colony Stimulating Factor 1}

Variants at the colony stimulating factor 1 (CSF1) locus on chromosome $1 \mathrm{p} 13$ were identified as predisposing to PDB by a GWAS study in 2010 [31••] and replicated in a further GWAS study [32••] more recently. The CSF1 gene encodes macrophage-colony stimulating factor (M-CSF). This protein has a critical role in osteoclast formation and survival and is a strong functional candidate for PDB susceptibility [33]. The M-CSF protein binds to its receptor (c-FMS), resulting in a signalling cascade which leads to the activation of ERK (extracellular signal-regulated kinase) and AKT (protein kinase $\mathrm{B})$, activating genes that promote the proliferation and survival of osteoclast precursors. Clinical studies have shown that patients with PDB have increased serum levels of M-CSF, supporting the role of $C S F 1$ in the pathogenesis of PDB [34]. The single nucleotide polymorphisms (SNPs) associated with PDB are located upstream of the gene in a region rich in regulatory elements, suggesting that the association may be due to an effect on regulation of $C S F 1$ expression but the exact mechanisms by which these variants predispose to PDB remain to be established.

\section{Heterogeneous Nuclear Ribonucleoproteins}

Mutations in the heterogeneous nuclear ribonucleoprotein A2/ $\mathrm{B} 1(h n R N P A 2 B 1)$ and $h n R N P A 1$ genes were identified as a cause of multisystem proteinopathy in which PDB was a component part by a genome sequencing approach in families $[35 \bullet \cdot]$. The disease-causing mutations increase the propensity of the proteins to assemble into fibrils and to be recruited into cytoplasmic 'stress granules' (reviewed by Ralston and Taylor $\left.\left[30^{\bullet}\right]\right)$. It is of interest that a family has been described in which a PP310L mutation in $h n R N P A 2 B 1$ occurred in patients with PDB who did not experience myopathy or neurodegeneration $\left[36^{\bullet}\right]$.

\section{Nucleoporin 205}

The nucleoporin 205 (NUP205) gene on chromosome 7q33 was identified as possible candidate for PDB by an extended GWAS in 2011 [32••]. The strongest signal was with the rs4294134 within intron 22 of the gene. The NUP205 protein is involved in the nuclear pore complex (NPC) which is 

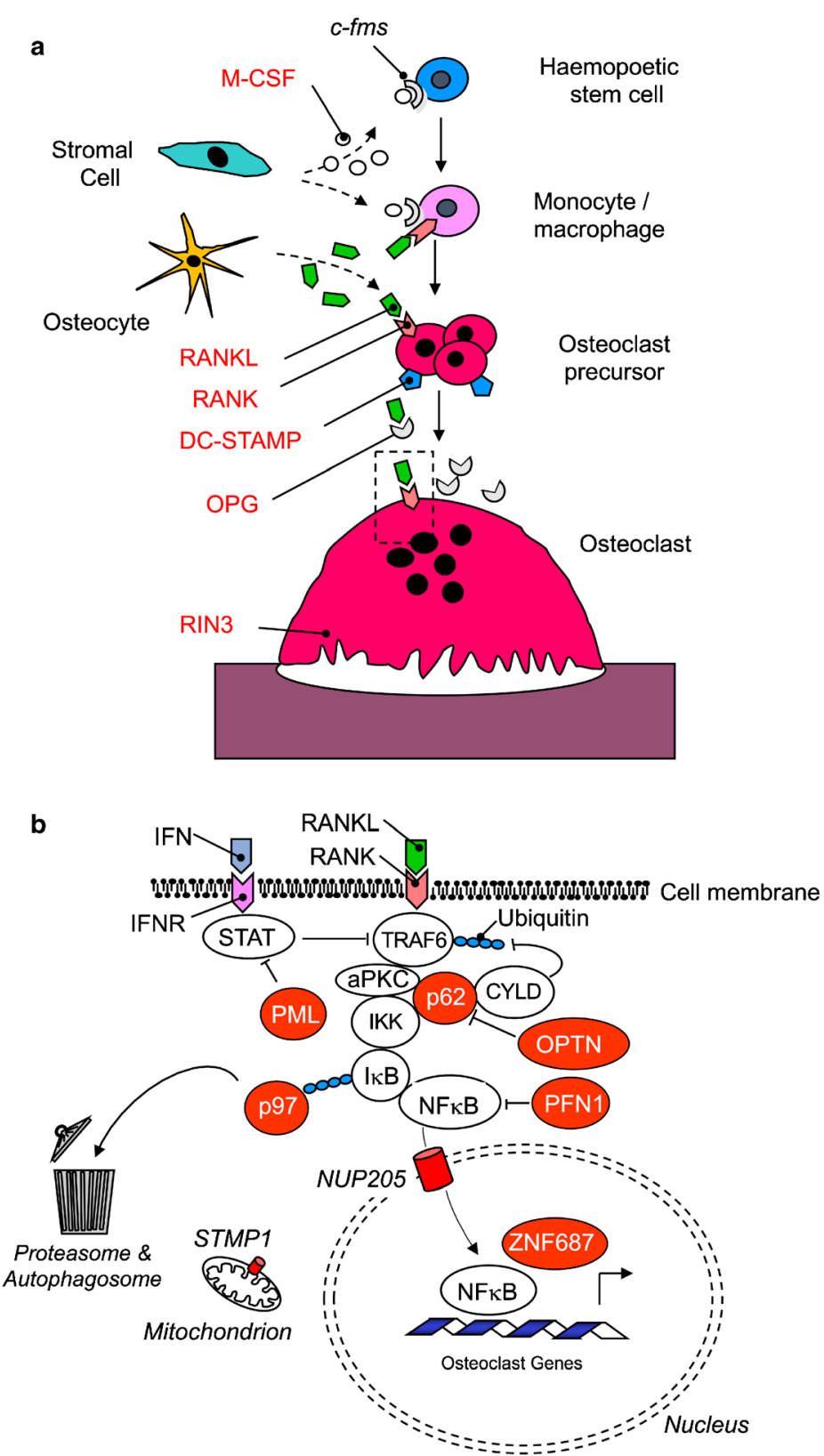

Fig. 1 Genes implicated in Paget's disease and related syndromes. Panel a shows some genes implicated in the pathogenesis of PDB which have effects on osteoclast differentiation and bone resorption. The gene products implicated in PDB are highlighted in red text. Panel $\mathbf{b}$ shows genes thought to affect intracellular signalling in osteoclasts and osteoclast precursors. The implicated gene products are highlighted in red and mostly affect the NFKB signalling pathway by interacting with SQSTM1 or genes that regulate signalling downstream of the RANK receptor. The ZNF678 gene encodes a transcription factor, but the exact mechanisms by which it predisposes to PDB are unclear. Abbreviations: c-fms - Colony Stimulating Factor 1 Receptor; M-CSF - Macrophage

responsible for transport of molecules from the cytoplasm to the nucleus. The role of NUP205 in bone is currently unclear, but a previous study demonstrated that inactivating missense mutations in NUP205 are associated with steroid-resistant nephrotic syndrome [37, 38]. Another gene within the $7 \mathrm{q} 33$
Colony Stimulating factor; RANK - Receptor Activator of Nuclear Factor Kappa B; RANKL - RANK Ligand; DC-STAMP - Dendritic Cell Specific Transmembrane Protein; OPG - Osteoprotegerin; RIN3 Ras and Rab Interactor 3; IFN - Interferon; IFNR - Interferon Receptor; STAT - Signal Transducers and Activators of Transcription; TRAF 6 Tumour Necrosis Factor Receptor Associated Factor 6; CYLD Cylindromatosis; p62 - Sequestosome 1; aPKC - atypical Protein Kinase C; IKK - Inhibitor of Kappa B Kinase; IkB - Inhibitor of Kappa B; NFkB - Nuclear Factor Kappa B; OPTN - Optineurin, PFN1 - Profilin 1; NUP205 - Nucleoporin 205; ZNF687 - Zinc Finger Protein 687; Short Transmembrane Mitochondrial Protein 1.

locus that may be a stronger candidate is $S T M P 1$ which is also located within the 7q33 locus. Mullin and colleagues recently reported that rs4294134 was an expression quantitative trait locus for STMP1 which was found to be expressed in a human osteoclast specific cDNA library [39॰]. The STMP1 gene 
encodes a short transmembrane mitochondrial protein whose function in bone is unclear.

\section{Optineurin}

The optineurin gene (OPTN) on chromosome 10p13 was identified as a candidate for PDB by linkage studies in families [40] and GWAS studies [31••, 32••]. The strongest association in GWAS was observed with the rs1561570 variant within the OPTN gene which increased the risk of PDB by about 1.6-fold. The OPTN gene encodes optineurin, which is a widely expressed cytoplasmic protein with multiple cellular functions, including in NFKB signalling [41], autophagy, and innate immunity [42]. Previous studies have identified a negative regulatory role for $O P T N$ in osteoclast differentiation by modulating $\mathrm{NF} \kappa \mathrm{B}$ and interferon signalling both in vitro and in vivo in mouse models [43]. It has been shown that OPTN appears to negatively regulate RANKL-induced NFKB activation in osteoclast precursors by a mechanism requiring ubiquitin binding and involves an interaction with CYLD [43]. Knockdown of optineurin in bone marrow-derived macrophages was found to enhanced osteoclast differentiation and hypernucleation [43]. Furthermore, mice with a loss of function mutation in Optn exhibited enhance bone turnover and increased sensitivity of osteoclast precursors to RANKL stimulation [43]. The predisposing variant in humans is associated with significantly reduced $O P T N$ mRNA expression. This indicates that $O P T N$ is a negative regulator of osteoclast differentiation and function and that the predisposing variant in humans reduces $O P T N$ expression, thereby increasing osteoclast activity.

\section{Promyelocytic Leukaemia Gene}

The promyelocytic leukaemia gene (PML) on 15q24.1 was identified as a candidate for PDB following a GWAS study in 2011 [32••]. Although the locus contains two genes, PML was the most obvious candidate. The $P M L$ gene gained its name as it was discovered as a tumour suppressor that is disrupted in acute promyelocytic leukaemia resulting in its fusion to the gene retinoic acid receptor alpha $(R A R A)$ [44]. It has also been shown to be involved in multiple other cellular pathways, such as in regulation of cell growth, senescence, apoptosis, DNA repair, stem cell maintenance, protein degradation, autophagy, and antiviral responses [45]. Furthermore, it appears to maintain genome integrity and stability through recognition of DNA damage and organisation of multiple DNA repair complexes [46, 47].

Until recently the role of $P M L$ in bone metabolism was unknown, but previous studies suggested that it may regulate myeloid cell differentiation, proliferation, and osteogenic differentiation of mesenchymal stem cells [48, 49]. Recent preliminary studies published in abstract form have shown that
PDB patients have reduced levels of PML expression compared with controls, and in vitro and in vivo studies have revealed that decreased expression of $P M L$ leads to increased osteoclast differentiation and activity [50]. Although the mechanisms by which $P M L$ variants predispose to PDB in humans are incompletely understood, it seems likely that they do so by increasing osteoclast differentiation and function.

\section{Profilin 1}

A frameshift mutation in the profilin 1 gene (PFN1) was identified as a cause of severe early-onset PDB by a genome sequencing approach in a large family from Campania in Italy $[51 \bullet \bullet$. Interestingly, three members of the family also developed osteosarcoma at a relatively young age. The causal mutation was predicted to produce a truncated variant of the gene product profilin-1. Functional studies showed that the abnormal protein increased osteoclast formation and multinuclearity in vitro in RAW273 cells and that the truncated protein also formed abnormal aggregates when expressed in a neuroblastoma cell line $[51 \bullet \bullet$. Further studies also demonstrated evidence for loss-of-heterozygosity for the PFN1 gene in about $2 \%$ of patients with sporadic PDB from the same region of Italy. It is of interest that previously, mutations of PFN1 had been identified by other investigators as a cause of amyotrophic lateral sclerosis (ALS) and that when the abnormal proteins were studied in vitro, insoluble protein aggregates were formed [52]. From these observations, it would appear that PFN1-mediated PDB may represent an example of multisystem proteinopathy, recently coined as the subtype 'multisystem proteinopathy 7 (MSP7)’ [53].

\section{Ras and Rab Interactor 3}

The Ras and Rab interactor (RIN3) gene on chromosome $14 \mathrm{q} 33$ was identified as a candidate for PDB by extended GWAS. The strongest signal was tagged by the SNP rs10498635 within the gene encoding RIN3. The RIN3 gene encodes Rab and Ras interactor protein 3, which acts as a guanine nucleotide exchange factor (GEF) for the Rab5 family of proteins including Rab5 itself and RAb31 [54]. Members of the RIN family interact with various proteins through functional domains they share, playing a role in endocytosis, vesicular trafficking, and signal transduction. These proteins are known to have a role in regulating osteoclast function through their effects on vesicular trafficking, but until recently, the role of RIN3 in bone metabolism had not been specifically studied [55]. Functional studies have shown that RIN3 mRNA is expressed in bone tissue and its expression level is approximately 10-fold higher in osteoclasts compared with osteoblasts [56]. The same authors also detected Rin3 protein in human osteoclasts from bone sections of a patient with giant cell tumour of bone, [56]. Functional studies have 
shown that $\operatorname{Rin} 3^{-/-}$mice have increased bone mass and reduced osteoclastic bone resorption in vivo but that osteoclast differentiation and survival in vitro are normal [57]. From this it was concluded that likely variants in RIN3 predispose to PDB through a gain-in-function. Interestingly Pavlos et al. [58] found a similar phenotype in mice with inactivation of the small GTPase Rab3D (a potential target for RIN3), raising the possibility that RIN3 may act as a GEF not only for the Rab5 sub-family of GTPases as has previously been reported [58-59] but also for Rab3D [59]. Having said that, further investigation is required to evaluate the specific pathway by which variants in RIN3 produce their observed phenotypic effects.

\section{Transcription Factor SP7}

The transcription factor SP7 gene (SP7) was identified by Whyte and colleagues as a potential cause of early-onset PDB in a patient with an osteosclerotic disorder characterised by high bone mass, bone deformity, and pathological fractures during childhood. The patient had a raised serum ALP, hypertelorism, and a broad forehead with prominence of the frontal bone. There were bowing deformities of both femora. The clinical features were felt to be consistent with juvenile PDB [60•]. Genetic analysis revealed a heterozygous mutation at codon 309 (pS309T) causing a substitution of tryptophan for serine in a conserved region of the SP7 gene product, Osterix. Histological analysis showed evidence of woven bone, but this did not show the characteristic features of increased osteoclastic bone resorption that is usual in PDB. The SP7 gene encodes Osterix, a transcription factor essential for osteoblast differentiation. Loss of function mutations in SP7 are a recognised cause of osteogenesis imperfecta, and this is thought to occur as the result of reduced bone formation. It therefore seems likely that the pS309T mutation causes gain of function of Osterix and works by increasing bone formation, leading to production of woven bone and associated bone deformity and increased bone fragility.

\section{Sequestosome 1}

Mutations in the sequestosome 1 (SQSTM1) gene were identified by genome wide linkage studies as a cause of familial PDB in two independent populations [27, 28]. Researchers in Quebec identified a proline to leucine mutation at codon 392 of the protein (P392L) as a cause of the disease [61], and soon after, this and other mutations were identified in the ubiquitinassociated (UBA) domain as the cause of the disease in people of UK descent [62]. A large number of SQSTM1 mutations have now been reported in PDB patients across the world, most of which affect the UBA domain [61-65]. The frequency with which SQTSM1 mutations occur in PDB varies in different countries, but in the UK, it has been estimated that they occur in about $40 \%$ of familial PDB cases and up to $10 \%$ of sporadic cases $[25,66]$. The SQSTM1 gene encodes p62, an adaptor protein in the NFKB signalling pathway [67]. This protein has a role in regulation of signalling downstream of the RANK, tumour necrosis factor (TNF), and neurotrophic growth factor (NGF) receptors [68] but also appears to play a key role in regulating other cellular processes through its involvement in autophagy [69-71]. This has recently been shown to be dysregulated in preclinical models of SQSTM1mediated PDB [72] and by the finding of associations between SNP of genes in the autophagy pathway and PDB [73].

The mechanisms by which mutations in SQSTM1 lead to PDB are not yet fully understood, but a common feature is their interference in the ability of p62 to bind ubiquitin [74]. This leads to enhanced NFkB signalling and increased sensitivity of osteoclast precursors to RANK-ligand (RANKL).

\section{Transmembrane 7 Superfamily Member 4}

The transmembrane 7 superfamily member 4 (TM7SF4) gene on chromosome $8 \mathrm{q} 22$ encodes a seven-pass transmembrane protein that is primarily expressed in dendritic cells. It was identified as being associated with PDB by an extended GWAS in 2011 [32••]. The strongest association was within an 18-kb linkage disequilibrium block spanning the TM7SF4 gene. There is a strong functional rationale for this being a candidate gene for PDB since it encodes a dendritic cellspecific transmembrane protein (DC-STAMP) which is upregulated by RANKL in osteoclast precursors [75] where it is required for fusion of osteoclast precursors to form mature osteoclasts [76]. A potential ligand for DC-STAMP is connective tissue growth factor (CCN2) which results in stimulation of osteoclastogenesis [77].

The variant identified by GWAS is also an expression quantitative trait locus for expression of TM7SF4 in peripheral blood monocytes and osteoclasts raising the possibility that variants at this locus predispose to PDB by upregulating TM7SF4 expression, thereby enhancing osteoclast fusion [39•, 78]. Some rare variants have also been identified in the protein coding region of TM7SF4 in patients with PDB, but it is unclear what effects they have on protein function.

\section{Tumour Necrosis Factor Receptor Superfamily Member 11A}

The tumour necrosis factor receptor superfamily member $11 \mathrm{~A}$ (TNFSRF11A) gene on chromosome 18q21 encodes receptor activator of nuclear factor kappa B (RANK) which is a signalling molecule that plays an essential role in osteoclast differentiation and function. The TNFRSF11A gene was first implicated in the pathogenesis of PDB through linkage studies followed by positional cloning in familial expansile osteolysis (FEO) and early-onset familial Paget's disease which 
identified mutations affecting the first exon of RANK as the cause of both disorders [79]. Subsequently similar mutations were identified as the cause of expansile skeletal hyperphosphatasia and panostotic expansile bone disease [30•]. The responsible mutations are duplications of between 15 and 27 nucleotides in the first exon of TNFRSF11A which add between five and nine additional amino acid residues into the RANK signal peptide, preventing its cleavage [79]. The abnormal RANK molecules accumulate in the Golgi apparatus [80] and promote osteoclast differentiation, probably by activating the unfolded protein response. Linkage studies in classical PDB also showed linkage to the same region of $18 \mathrm{q} 21$ with genetic heterogeneity [81] leading to investigations of the role of TNFRSF11A in classical PDB [82]. An association was observed with rs 1805034 which codes for an alanine to valine amino acid change at codon 192 (pA192V). A significant association between pA192V and PDB was also reported in a case control study in an Italian population [83]. The mechanism by which the pA192V polymorphism predisposes to PDB is unclear since in silico analysis has predicted it to be a conservative change and functional studies have not showed differences in the ability of the two variants to stimulate $\mathrm{NFKB}$ activation in vitro [82]. The candidacy of TNFRSF11A as a predisposing gene for classical PDB was confirmed by a genome wide association study which showed association between PDB and the rs2957128 and rs3018362 variants in the 3' flank of the TNFRSF11A gene $[31 \bullet \cdot$. These variants are in moderate linkage disequilibrium with the pV192A variant, but at the present time, the molecular mechanisms by which TNFRSF11A variants predispose to PDB are incompletely understood.

\section{Tumour Necrosis Family Receptor Superfamily Member 11B}

Loss of function mutations in the tumour necrosis family receptor superfamily member $11 \mathrm{~B}$ gene (TNFRSF11B) were identified as a cause of the syndrome of juvenile PDB. This is a rare recessive disorder associated with grossly abnormal bone remodelling, bone expansion, and bone deformity presenting in childhood and adolescence. It is caused by various loss of function mutations affecting TNFRSF11B [84] which encodes osteoprotegerin (OPG), an inhibitor of osteoclast differentiation and function $[84,85]$. Mutations of TNFRSF11B have not yet been detected in classical PDB, but there is some evidence from association studies to suggest that common variants at the TNFRSF $11 B$ locus may predispose to PDB in women but not men [86, 87].

\section{Valosin-Containing Protein}

Mutations in the valosin-containing protein $(V C P)$ gene were identified as the cause of the syndrome of hereditary inclusion body myopathy, PDB, and frontotemporal dementia (IBMPFD) [88]. The VCP gene encodes p97 which is a multifunctional protein involved in several intracellular processes including NFKB signalling, DNA repair, and autophagy. The mechanisms of neurological dysfunction and myopathy are incompletely understood but are likely to involve a general defect in ubiquitin mediated protein degradation with accumulation of abnormal protein aggregates which cause cellular toxicity. The PDB component is less well understood but may be due at least in part to increased sequestration of IKB with activation of NFKB. Since its original description, the IBMPFD syndrome associated with VCP mutations has been reclassified as one of the multisystem proteinopathies, which are multisystem disorders in which neurological and muscle dysfunction are sometimes accompanied by PDB [89].

\section{Zinc Finger Protein 687}

Mutations in the zinc finger protein 687 (ZNF687) gene were identified as a cause of severe early-onset PDB by a genome sequencing approach in a large family with autosomal dominant inheritance of PDB from the Campania region of Italy [90••]. The PDB was accompanied by giant cell tumour (CGT) in 4/14 (28.5\%) of affected patients from this family. The causal mutation in the index family was a proline to arginine amino acid substitution at codon 937 (pP937R) of ZNF687. Subsequently sequencing of other families from the same region identified the same mutation and another mutation which causes a serine to isoleucine amino change at codon 242 (pS242I). The mechanisms by which these mutations in ZNF687 affect bone metabolism to cause PDB and GCT remain unclear. Expression of ZNF687 increases during osteoclastogenesis following M-CSF and RANKL treatment of human monocytes. The gene is also expressed in monocytes, osteoclasts, and osteoblasts in zebrafish, and high levels of ZNF687 mRNA have also been found in GCT. While bioinformatic analysis has predicted that the pP937R mutation may enhance nuclear import of ZNF687, the consequences of this are unclear.

\section{Pharmacogenetics and PDB}

The importance of genetic factors in PDB raises the possibility that genetic profiling might be of value clinically in identifying those at risk of the disease and also in providing markers of response to treatment. Both of these issues are discussed in the present section.

\section{Genetic Markers for Susceptibility to PDB}

The importance of genetic factors in PDB coupled with the observation that risk variants have a large effect size raises the 
possibility that genetic testing could be of value in identifying patients at risk of developing PDB or those at risk of complications [91]. This is particularly relevant in the rare syndromic forms of PDB where the disease is inherited in a Mendelian manner where genetic testing is already performed in children of affected individuals. The potential role of genetic testing coupled to therapeutic intervention is currently being explored in the context of the ZiPP trial (ISRCTN 11616770). In this study, adults who had a family history of PDB were offered genetic testing for SQSTM1 mutations, and those that tested positive were invited to take part in a randomised controlled trial of zoledronic acid or placebo with the aim of determining whether treatment was effective at preventing the development of PDB [92]. Analysis of baseline characteristics showed that about 9\% of SQSTM1 mutation carriers had signs of PDB on bone scan but were asymptomatic, and interestingly, most people with lesions had normal levels of biochemical markers of bone remodelling [93•]. The study remains in progress but is due to report during 2021. Another approach used by GuayBelanger and colleagues combined both a genetic screening test for SQSTM1 mutations, with a test for biochemical markers associated with PDB [94]. This approach correctly identified 93.9\% of PDB-affected patients as compared with controls. Similarly, Albagha and colleagues evaluated the performance of seven SNPs associated with PDB derived from GWAS with mutations in SQSTM1 to try and predict extent and severity of PDB in a multinational cohort of 1940 patients with the disease. The approach was successful in identifying disease extent, complications, and number of courses of bisphosphonates administered [91]. Both Guay-Belanger's study and Albagha's study focused on patients known to have PDB rather than those at risk because of positive family history, and a future aim will be to further explore the risk of genetic and other markers in predicting risk of developing the disease.

\section{Genetic Markers of Treatment Response}

Several investigators have explored the possible role of genetic profiling in assessing treatment response [95-97]. Bisphosphonates are generally considered to be the treatment of first choice for PDB, and modern bisphosphonates can induce biochemical remission in the majority of PDB patients [98, 99]. Some investigators have studied so-called acquired resistance to bisphosphonate therapy in PDB, although these studies typically involved patients treated with older bisphosphonates [95, 100-102]. Mossetti and colleagues [96] studied the relation between the TaqI, BsmI, and Fokl polymorphisms in the VDR gene and response to clodronate in 84 patients with PDB as well as possible associations between SQSTM1 mutations and treatment response in the same population. They reported a significant association between the TaqI and BsmI polymorphisms and resistance to $1500 \mathrm{mg}$ clodronate given intravenously by logistic regression analysis taking other predictors into account.
Resistance was defined as lack of suppression of ALP level by more than $50 \%$ compared with the starting value. The duration of response was also related to $V D R$ alleles. There was no difference however in the proportion of patients with SQSTM1 mutations in the groups of patients with resistance or no resistance to clodronate. Corral-Gudino and colleagues [95] studied the relation between polymorphisms in the ILIB, ILRI, and ILIRN genes and response to treatment with various bisphosphonates including etidronate, tiludronate, clodronate, risedronate and pamidronate in 123 patients with PDB. The ILIB gene encodes interleukin- 1 beta a cytokine with stimulatory effects on osteoclasts; the ILRI gene encodes the interleukin 1 receptor, and the $I L I R N$ gene encodes the interleukin-1 receptor antagonist. They reported that the $-511 \mathrm{C} / \mathrm{T}$ polymorphism of the $I L 1 B$ gene was significantly associated with response to all bisphosphonates grouped together [95]. Analysis of response to individual bisphosphonates revealed notionally significant results for tiludronate and risedronate, but the analyses were not corrected for multiple testing. The mechanisms of acquired resistance to bisphosphonate therapy in PDB remain poorly understood, but several theories are proposed. The first is that bisphosphonate therapy may select a subgroup of osteoclasts that become resistant to the apoptotic effect of the drug [103]. The second is that continued therapy with a bisphosphonate may induce enzymes that confer resistance to a subset of osteoclasts or their precursors [103]. It has also been proposed that acquired resistance is caused by disease-related factors and patients with extensive PDB are more likely to develop resistance. These studies, while of interest, were both based on small sample size, and the results will be required to be replicated in other populations. More recently Visconti looked at the relation between SQSTM1 mutations and treatment response in the PRISM study [97]. While carriers of SQSTM1 mutations were found to have more severe disease, there was no difference between those with and without SQSTM1 mutations and response to treatment.

\section{Conclusion}

Genetic factors play a key role in the pathogenesis of Paget's disease, and huge advances have been made over the past 20 years in identifying the genetic variants that predispose to the disease and the mechanisms by which they affect bone metabolism. Further research needs to be conducted to identify additional genes that cause the disease however, and it is likely that extended GWAS studies, genome sequencing studies, and candidate gene studies may cast further light into disease mechanisms in the future. An important direction will be to further explore the mechanisms by which genetic variants and environmental factors interact to influence susceptibility and disease severity, since this is an area that is poorly understood. Advances in genetics offer the prospect of developing a more comprehensive understanding of the pathophysiology of PDB and open the possibility of using 
genetic testing coupled to targeted therapeutic intervention to prevent disease progression and improve outcome before irreversible skeletal damage has occurred.

Acknowledgments This publication is part of a project that has received funding from the European Research Council (ERC) in the form of an advanced investigator award to SHR under the European Union's Horizon 2020 research and innovation programme (Grant agreement No. 787270 ).

\section{Declarations}

Conflict of Interest Professor Ralston reports grants from the European Commission during the conduct of the study and grants from Amgen, Eli Lilly, Novartis, and Pfizer, outside the submitted work; Mr Makaram declares no conflict of interest.

Human and Animal Rights and Informed Consent This article does not contain any studies with human or animal subjects performed by any of the authors.

Open Access This article is licensed under a Creative Commons Attribution 4.0 International License, which permits use, sharing, adaptation, distribution and reproduction in any medium or format, as long as you give appropriate credit to the original author(s) and the source, provide a link to the Creative Commons licence, and indicate if changes were made. The images or other third party material in this article are included in the article's Creative Commons licence, unless indicated otherwise in a credit line to the material. If material is not included in the article's Creative Commons licence and your intended use is not permitted by statutory regulation or exceeds the permitted use, you will need to obtain permission directly from the copyright holder. To view a copy of this licence, visit http://creativecommons.org/licenses/by/4.0/.

\section{References}

Papers of particular interest, published recently, have been highlighted as:

- Of importance

•. Of major importance

1. Makaram N, Woods L, Beattie N, Roberts SB, MacPherson GJ. Long-term outcomes following total hip and total knee arthroplasty in patients with Paget's disease of bone (PDB) - a national study. Surgeon. 2020;S149-666X:30150-301507.

2. van Staa TP, Selby P, Leufkens HG, Lyles K, Sprafka JM, Cooper C. Incidence and natural history of Paget's disease of bone in England and Wales. J Bone Miner Res. 2002;17:465-71.

3. Gianfrancesco F, Rendina D, Merlotti D, Esposito T, Amyere M, Formicola D, et al. Giant cell tumor occurring in familial Paget's disease of bone: report of clinical characteristics and linkage analysis of a large pedigree. J Bone Miner Res. 2013;28:341-50.

4. Barker DJ. The epidemiology of Paget's disease of bone. Br Med Bull. 1984;40:396-400.

5. Detheridge FM, Guyer PB, Barker DJ. European distribution of Paget's disease of bone. Br Med J (Clin Res Ed). 1982;285:10058 .
6. Corral-Gudino L, Borao-Cengotita-Bengoa M, Del Pino-Montes J, Ralston SH. Epidemiology of Paget's disease of bone: a systematic review and meta-analysis of secular changes. Bone. 2013;55:347-52.

7. Ralston SH. Clinical practice. Paget's disease of bone. N Engl J Med. 2013;368:644-50.

8. Cundy HR, Gamble G, Wattie D, Rutland M, Cundy T. Paget's disease of bone in New Zealand: continued decline in disease severity. Calcif Tissue Int. 2004;75:358-64.

9. Poór G, Donáth J, Fornet B, Cooper C. Epidemiology of Paget's disease in Europe: the prevalence is decreasing. J Bone Miner Res. 2006:21:1545-9.

10. Gennari L, Gianfrancesco F, Di Stefano M, Rendina D, Merlotti D, Esposito T, et al. SQSTM1 gene analysis and geneenvironment interaction in Paget's disease of bone. J Bone Miner Res. 2010;25:1375-84.

11. Gennari L, Merlotti D, Martini G, Nuti R. Paget's disease of bone in Italy. J Bone Miner Res. 2006;21 Suppl 2:P14-21.

12. Tiegs RD, Lohse CM, Wollan PC, Melton LJ. Long-term trends in the incidence of Paget's disease of bone. Bone. 2000;27:423-7.

13. Ralston SH, Corral-Gudino L, Cooper C, Francis RM, Fraser WD, Gennari L, et al. Diagnosis and management of Paget's disease of bone in adults: a clinical guideline. J Bone Miner Res. 2019;34: 579-604.

14. Siris ES. Epidemiological aspects of Paget's disease: family history and relationship to other medical conditions. Semin Arthritis Rheum. 1994;23:222-5.

15. Barker DJ, Gardner MJ. Distribution of Paget's disease in England, Wales and Scotland and a possible relationship with vitamin D deficiency in childhood. Br J Prev Soc Med. 1974;28: 226-32.

16. Solomon LR. Billiard-player's fingers: an unusual case of Paget's disease of bone. Br Med J. 1979;1:931.

17. Michou L, Collet C, Morissette J, Audran M, Thomas T, Gagnon E, et al. Epidemiogenetic study of French families with Paget's disease of bone. Joint Bone Spine. 2012;79:393-8.

18. Audet MC, Jean S, Beaudoin C, Guay-Bélanger S, Dumont J, Brown JP, et al. Environmental factors associated with familial or non-familial forms of Paget's disease of bone. Joint Bone Spine. 2017;84:719-23.

19. Adachi JD, Arlen D, Webber CE, Chettle DR, Beaumont LF, Gordon CL. Is there any association between the presence of bone disease and cumulative exposure to lead? Calcif Tissue Int. 1998;63:429-32.

20. Spencer H, Sontag SJ. Occupational and environmental exposure to lead and Paget's disease of bone. Environ Int. 1994;20:619-26.

21. Barker DJ, Chamberlain AT, Guyer PB, Gardner MJ. Paget's disease of bone: the Lancashire focus. Br Med J. 1980;280: 1105-7.

22. Merlotti D, Gennari L, Galli B, Martini G, Calabrò A, De Paola V, et al. Characteristics and familial aggregation of Paget's disease of bone in Italy. J Bone Miner Res. 2005;20:1356-64.

23. Visconti MR, Usategui-Martin R, Ralston SH. Antibody response to paramyxoviruses in Paget's disease of bone. Calcif Tissue Int. 2017;101:141-7.

24. Gennari L, Rendina D, Falchetti A, Merlotti D. Paget's disease of bone. Calcif Tissue Int. 2019;104:483-500.

25. Morissette J, Laurin N, Brown JP. Sequestosome 1: mutation frequencies, haplotypes, and phenotypes in familial Paget's disease of bone. J Bone Miner Res. 2006;21(Suppl 2):P38-44.

26. Morales-Piga AA, Rey-Rey JS, Corres-González J, GarcíaSagredo JM, López-Abente G. Frequency and characteristics of familial aggregation of Paget's disease of bone. J Bone Miner Res. 1995; 10:663-70.

27. Hocking LJ, Herbert CA, Nicholls RK, Williams F, Bennett ST, Cundy T, et al. Genomewide search in familial Paget disease of 
bone shows evidence of genetic heterogeneity with candidate loci on chromosomes 2q36, 10p13, and 5q35. Am J Hum Genet. 2001;69:1055-61.

28. Laurin N, Brown JP, Lemainque A, Duchesne A, Huot D, Lacourcière $\mathrm{Y}$, et al. Paget disease of bone: mapping of two loci at 5q35-qter and 5q31. Am J Hum Genet. 2001;69:528-43.

29. Siris ES, Ottman R, Flaster E, Kelsey JL. Familial aggregation of Paget's disease of bone. J Bone Miner Res. 1991;6:495-500.

30. Ralston SH, Taylor JP. Rare inherited forms of Paget's disease and related syndromes. Calcif Tissue Int. 2019;104:501-16 Comprehensive review article providing detail on the genes and mechanisms involved in the pathogenesis of rare inherited syndromes with similarity to PDB.

31・. Albagha OM, Visconti MR, Alonso N, Langston AL, Cundy T, Dargie R, et al. Genome-wide association study identifies variants at CSF1, OPTN and TNFRSF11A as genetic risk factors for Paget's disease of bone. Nat Genet. 2010;42:520-4 The first genome wide association study to be performed in Paget's disease identifying loci of moderately large effect size as predisposing factors for the disease.

32•. Albagha OM, Wani SE, Visconti MR, Alonso N, Goodman K, Brandi ML, et al. Genome-wide association identifies three new susceptibility loci for Paget's disease of bone. Nat Genet. 2011;43:685-9 An extended genome wide association study which increased the number of loci to be associated with Paget's disease from three to six.

33. Tsurukai T, Udagawa N, Matsuzaki K, Takahashi N, Suda T. Roles of macrophage-colony stimulating factor and osteoclast differentiation factor in osteoclastogenesis. J Bone Miner Metab. 2000;18:177-84.

34. Neale SD, Schulze E, Smith R, Athanasou NA. The influence of serum cytokines and growth factors on osteoclast formation in Paget's disease. QJM. 2002;95:233-40.

35••. Kim HJ, Kim NC, Wang YD, Scarborough EA, Moore J, Diaz Z, et al. Mutations in prion-like domains in hnRNPA2B1 and hnRNPA1 cause multisystem proteinopathy and ALS. Nature. 2013;495:467-73 A genome sequencing study coupled with elegant functional studies on the mutated proteins which identified missense mutations in the hnRNPA2B1 and hnRNPA1 genes as causes of Paget's disease and multisystem proteinopathy in which neurodegeneration and myopathy occurred in some individuals. This provided further evidence that inclusion bodies seen in Paget's disease may represent abnormal protein aggregates as opposed to viral particles.

36•. Qi X, Pang Q, Wang J, Zhao Z, Wang O, Xu L, et al. Familial early-onset Paget's disease of bone associated with a novel hnRNPA2B1 mutation. Calcif Tissue Int. 2017;101:159-69 Case report demonstrating that a mutation in hnRNPA2B1 can cause $P D B$ in the absence of neurodegeneration or myopathy.

37. Braun DA, Lovric S, Schapiro D, Schneider R, Marquez J, Asif $\mathrm{M}$, et al. Mutations in multiple components of the nuclear pore complex cause nephrotic syndrome. J Clin Invest. 2018;128: 4313-28.

38. Braun DA, Sadowski CE, Kohl S, Lovric S, Astrinidis SA, Pabst WL, et al. Mutations in nuclear pore genes NUP93, NUP205 and XPO5 cause steroid-resistant nephrotic syndrome. Nat Genet. 2016;48:457-65.

39•. Mullin BH, Zhu K, Brown SJ, Mullin S, Tickner J, Pavlos NJ, et al. Genetic regulatory mechanisms in human osteoclasts suggest a role for the STMP1 and DCSTAMP genes in Paget's disease of bone. Sci Rep. 2019;9:1052 An eQTL study of human osteoclasts showing that variants that predispose to PDB at the $8 q 22$ and $7 q 33$ loci identified by GWAS are expression quantitative trait loci for DCSTAMP and STMP1 respectively suggesting that these may be the candidate genes within these loci.

40. Lucas GJA, Riches PL, Hocking LJ, Cundy T, Nicholson GC, Walsh JP, et al. Identification of a major locus for Paget's disease on chromosome 10p13 in families of British descent. J Bone Miner Res. 2008;23:58-63.

41. Zhu G, Wu C-J, Zhao Y, Ashwell JD. Optineurin negatively regulates $\mathrm{TNF} \alpha$ - induced NF-KB activation by competing with NEMO for ubiquitinated RIP. Curr Biol. 2007;17:1438-43.

42. Wild P, Farhan H, McEwan DG, Wagner S, Rogov VV, Brady NR, et al. Phosphorylation of the autophagy receptor optineurin restricts Salmonella Growth. Science. 2011;333:228-33.

43. Obaid R, Wani SE, Azfer A, Hurd T, Jones R, Cohen P, et al. Optineurin negatively regulates osteoclast differentiation by modulating NF- $\mathrm{KB}$ and interferon signaling: implications for Paget's disease. Cell Rep. 2015;13:1096-102.

44. Nisole S, Maroui MA, Mascle X, Aubry M, Chelbi-Alix M. Differential roles of PML isoforms. Front Oncol. https://doi.org/ 10.3389/fonc.2013.00125

45. Guan D, Kao H-Y. The function, regulation and therapeutic implications of the tumor suppressor protein, PML. Cell Biosci. 2015;5:60.

46. Dellaire G, Bazett-Jones DP. PML nuclear bodies: dynamic sensors of DNA damage and cellular stress. Bioessays. 2004;26:96377.

47. Chung I, Osterwald S, Deeg KI, Rippe K. PML body meets telomere: the beginning of an ALTernate ending? Nucleus. 2012;3: 263-75.

48. El Bougrini J, Dianoux L, Chelbi-Alix MK. PML positively regulates interferon gamma signaling. Biochimie. 2011;93:389-98.

49. Ahmed A, Wan X, Mitxitorena I, Lindsay AJ, Paolo Pandolfi P, McCaffrey MW, et al. Regulation of NF-KB by PML and PMLRAR $\alpha$. Sci Rep. 2017;7:44539.

50. Wani S, Ralston SH, Albagha OME. The Paget's disease susceptibility gene PML, regulates osteoclast activity in vitro. Calcif Tissue Int. 2017;100: S143 (abstract)

51••. Scotto di Carlo F, Pazzaglia L, Esposito T, Gianfrancesco F. The loss of profilin 1 causes early onset Paget's disease of bone. J Bone Miner Res. 2020: 35:1387-1398. Identification of a loss of function mutation in Profilin 1 (PFN1) as a cause of severe early onset Paget's disease in a large family from the Campania region of Italy. A proportion of individuals also developed osteosarcoma indicating that PFN1 may have a role as a tumour suppressor. There was also evidence of loss of heterozygosity of PFN1 in other subjects with PDB from the same region.

52. Wu CH, Fallini C, Ticozzi N, Keagle PJ, Sapp PC, Piotrowska K, et al. Mutations in the profilin 1 gene cause familial amyotrophic lateral sclerosis. Nature. 2012;488:499-503.

53. Ralston SH. A new gene for susceptibility to Paget's disease of bone and for multisystem proteinopathy. J Bone Miner Res. 2020;35:1385-6.

54. Janson C, Kasahara N, Prendergast GC, Colicelli J. RIN3 is a negative regulator of mast cell responses to SCF. PLoS One. 2012;7:e49615.

55. Taylor A, Mules EH, Seabra MC, Helfrich MH, Rogers MJ, Coxon FP. Impaired prenylation of Rab GTPases in the gunmetal mouse causes defects in bone cell function. Small GTPases. 2011;2:131-42.

56. Vallet M, Soares DC, Wani S, Sophocleous A, Warner J, Salter $\mathrm{DM}$, et al. Targeted sequencing of the Paget's disease associated $14 \mathrm{q} 32$ locus identifies several missense coding variants in RIN3 that predispose to Paget's disease of bone. Hum Mol Genet. 2015;24:3286-95.

57. Vallet, M. Sophocleous, A, Tornqvist AE, Azfer A, van't Hof, RJ, Albagha OME, Ralston, SH,Targeted Inactivation of Rin3 
Increases Trabecular Bone Mass by Reducing Bone Resorption and Favouring Bone Formation. Calcified Tissue International 2021 https://doi.org/10.1007/s00223-021-00827-2

58. Pavlos NJ, Xu J, Riedel D, Yeoh JSG, Teitelbaum SL, Papadimitriou JM, et al. Rab3D regulates a novel vesicular trafficking pathway that is required for osteoclastic bone resorption. Mol Cell Biol. 2005;25:5253-69.

59. Yoshikawa M, Kajiho H, Sakurai K, Minoda T, Nakagawa S, Kontani K, et al. Tyr-phosphorylation signals translocate RIN3, the small GTPase Rab5-GEF, to early endocytic vesicles. Biochem Biophys Res Commun. 2008;372:168-72.

60• Whyte MP, Campeau PM, McAlister WH, Roodman GD, Kurihara N, Nenninger A, et al. Juvenile Paget's disease from heterozygous mutation of SP7 encoding osterix (specificity protein 7, transcription factor SP7). Bone. 2020;137:115364 An interesting case report in which a phenotype with similarity to Juvenile PDB was found in a patient with a gain of function in SP7 a gene known to affect osteoblast differentiation.

61. Laurin N, Brown JP, Morissette J, Raymond V. Recurrent mutation of the gene encoding sequestosome 1 (SQSTM1/p62) in Paget disease of bone. Am J Hum Genet. 2002;70:1582-8.

62. Hocking LJ, Lucas GJ, Daroszewska A, Mangion J, Olavesen M, Cundy $\mathrm{T}$, et al. Domain-specific mutations in sequestosome 1 (SQSTM1) cause familial and sporadic Paget's disease. Hum Mol Genet. 2002;11:2735-9.

63. Beyens G, Van Hul E, Van Driessche K, Fransen E, Devogelaer JP, Vanhoenacker F, et al. Evaluation of the role of the SQSTM1 gene in sporadic Belgian patients with Paget's disease. Calcif Tissue Int. 2004;75:144-52.

64. Falchetti A, Di Stefano M, Marini F, Ortolani S, Ulivieri MF, Bergui S, et al. Genetic epidemiology of Paget's disease of bone in Italy: sequestosome1/p62 gene mutational test and haplotype analysis at $5 \mathrm{q} 35$ in a large representative series of sporadic and familial Italian cases of Paget's disease of bone. Calcif Tissue Int. 2009;84:20-37.

65. Donath J, Balla B, Palinkas M, Rasonyi R, Vastag G, Alonso N, et al. Pattern of SQSTM1 gene variants in a Hungarian cohort of Paget's disease of bone. Calcif Tissue Int. 2021;108:159-164.

66. Langston AL, Campbell MK, Fraser WD, MacLennan GS, Selby PL, Ralston SH. Randomized trial of intensive bisphosphonate treatment versus symptomatic management in Paget's disease of bone. J Bone Miner Res. 2010;25:20-31.

67. Layfield R, Hocking LJ. SQSTM1 and Paget's disease of bone. Calcif Tissue Int. 2004;75:347-57.

68. Durán A, Serrano M, Leitges M, Flores JM, Picard S, Brown JP, et al. The atypical PKC-interacting protein p62 is an important mediator of RANK-activated osteoclastogenesis. Dev Cell. 2004;6:303-9.

69. Kirkin V, Lamark T, Johansen T, Dikic I. NBR1 cooperates with p62 in selective autophagy of ubiquitinated targets. Autophagy. 2009;5:732-3.

70. Kirkin V, Lamark T, Sou YS, Bjørkøy G, Nunn JL, Bruun JA, et al. A role for NBR1 in autophagosomal degradation of ubiquitinated substrates. Mol Cell. 2009;33:505-16.

71. Komatsu M, Waguri S, Koike M, Sou YS, Ueno T, Hara T, et al. Homeostatic levels of p62 control cytoplasmic inclusion body formation in autophagy-deficient mice. Cell. 2007;131:1149-63.

72. Daroszewska A, van't Hof RJ, Rojas JA, Layfield R, LandaoBasonga $\mathrm{E}$, Rose $\mathrm{L}$, et al. A point mutation in the ubiquitin associated domain of SQSMT1 is sufficient to cause a Paget's disease like disorder in mice. Hum Mol Genet. 2011;20:2734- 44.

73. Usategui-Martín R, García-Aparicio J, Corral-Gudino L, CaleroPaniagua I, Del Pino-Montes J, González Sarmiento R. Polymorphisms in autophagy genes are associated with Paget disease of bone. PLoS One. 2015;10:e128984.
74. Cavey JR, Ralston SH, Hocking LJ, Sheppard PW, Ciani B, Searle MS, et al. Loss of ubiquitin-binding associated with Paget's disease of bone p62 (SQSTM1) mutations. J Bone Miner Res. 2005;20:619-24.

75. Kukita T, Wada N, Kukita A, Kakimoto T, Sandra F, Toh K, et al. RANKL-induced DC-STAMP is essential for osteoclastogenesis. J Exp Med. 2004;200:941-6.

76. Yagi M, Miyamoto T, Sawatani Y, Iwamoto K, Hosogane N, Fujita N, et al. DC-STAMP is essential for cell-cell fusion in osteoclasts and foreign body giant cells. J Exp Med. 2005;202: $345-51$.

77. Nishida T, Emura K, Kubota S, Lyons KM, Takigawa M. CCN family 2 /connective tissue growth factor (CCN2/CTGF) promotes osteoclastogenesis via induction of and interaction with dendritic cell-specific transmembrane protein (DC-STAMP). J Bone Miner Res. 2011;26:351-63.

78. Zeller T, Wild P, Szymczak S, Rotival M, Schillert A, Castagne R, et al. Genetics and beyond - the transcriptome of human monocytes and disease susceptibility. PLoS One. 2010;5:e10693.

79. Hughes AE, Ralston SH, Marken J, Bell C, MacPherson H, Wallace RG, et al. Mutations in TNFRSF11A, affecting the signal peptide of RANK, cause familial expansile osteolysis. Nat Genet. 2000;24:45-8.

80. Crockett JC, Mellis DJ, Shennan KI, Duthie A, Greenhorn J, Wilkinson DI, et al. Signal peptide mutations in RANK prevent downstream activation of NF-KB. J Bone Miner Res. 2011;26: 1926-38.

81. Haslam SI, Van Hul W, Morales-Piga A, Balemans W, SanMillan JL, Nakatsuka K, et al. Paget's disease of bone: evidence for a susceptibility locus on chromosome $18 \mathrm{q}$ and for genetic heterogeneity. J Bone Miner Res. 1998;13:911-7.

82. Chung PYJ, Beyens G, Riches PL, Van Wesenbeeck L, de Freitas F, Jennes K, et al. Genetic variation in the TNFRSF11A gene encoding RANK is associated with susceptibility to Paget's disease of bone. J Bone Miner Res. 2010;25:2316-29.

83. Gianfrancesco F, Rendina D, Di Stefano M, Mingione A, Esposito $\mathrm{T}$, Merlotti D, et al. A nonsynonymous TNFRSF11A variation increases NFKB activity and the severity of Paget's disease. J Bone Miner Res. 2012;27:443-52.

84. Whyte MP, Obrecht SE, Finnegan PM, Jones JL, Podgornik MN, McAlister WH, Mumm S. Osteoprotegerin deficiency and juvenile Paget's disease. N. Engl. J Med 2002; 347:175-184.

85. Chong B, Hegde M, Fawkner M, Simonet S, Cassinelli H, Coker $\mathrm{M}$, et al. Idiopathic hyperphosphatasia and TNFRSF11B mutations: relationships between phenotype and genotype. J Bone Miner Res. 2003;18:2095-104.

86. Beyens G, Daroszewska A, de Freitas F, Fransen E, Vanhoenacker F, Verbruggen L, et al. Identification of sexspecific associations between polymorphisms of the osteoprotegerin gene, TNFRSF11B, and Paget's disease of bone. J Bone Miner Res. 2007;22:1062-71.

87. Daroszewska A, Hocking LJ, McGuigan FE, Langdahl B, Stone MD, Cundy T, et al. Susceptibility to Paget's disease of bone is influenced by a common polymorphic variant of osteoprotegerin. J Bone Miner Res. 2004;19:1506-11.

88. Watts GD, Wymer J, Kovach MJ, Mehta SG, Mumm S, Darvish D, Pestronk A, Whyte MP, Kimonis VE Inclusion body myopathy associated with Paget disease of bone and frontotemporal dementia is caused by mutant valosin-containing protein. Nat. Genet 2004;36:377-381.

89. Taylor JP. Multisystem proteinopathy: intersecting genetics in muscle, bone, and brain degeneration. Neurology. 2015;85:658 60 .

90••. Divisato G, Formicola D, Esposito T, Merlotti D, Pazzaglia L, Del FA, et al. ZNF687 Mutations in severe Paget disease of bone associated with giant cell tumor. Am J Hum Genet. 2016;98:275- 
86 Identification of mutations in the transcription factor ZNF687 as a cause of severe Paget's disease and Giant Cell Tumour in families from the Campania region of Italy.

91. Albagha OME, Visconti MR, Alonso N, Wani S, Goodman K, Fraser WD, et al. Common susceptibility alleles and SQSTM1 mutations predict disease extent and severity in a multinational study of patients with Paget's disease. J Bone Miner Res. 2013;28:2338-46.

92. Cronin O, Forsyth L, Goodman K, Lewis SC, Keerie C, Walker A, et al. Zoledronate in the prevention of Paget's (ZiPP): protocol for a randomised trial of genetic testing and targeted zoledronic acid therapy to prevent SQSTM1-mediated Paget's disease of bone. BMJ Open. 2019;9:e030689.

93. Cronin O, Subedi D, Forsyth L, Goodman K, Lewis SC, Keerie C, et al. Characteristics of early Paget's disease in SQSTM1 mutation carriers: baseline analysis of the ZiPP study cohort. J Bone Miner Res. 2020;35:1246-52 Baseline characteristics of the ZIPP study population demonstrating that by the age of about 50 years $9 \%$ of individuals had imaging evidence of PDB without symptoms.

94. Guay-Bélanger S, Simonyan D, Bureau A, Gagnon E, Albert C, Morissette J, et al. Development of a molecular test of Paget's disease of bone. Bone. 2016;84:213-21.

95. Corral-Gudino L, del Pino-Montes J, García-Aparicio J, Corral E, Montilla CA, González-Sarmiento R. -511 C/T IL1B gene polymorphism is associated to resistance to bisphosphonates treatment in Paget disease of bone. Bone. 2006;38:589-94.
96. Mossetti G, Gennari L, Rendina D, De Filippo G, Merlotti D, De Paola V, et al. Vitamin D receptor gene polymorphisms predict acquired resistance to clodronate treatment in patients with Paget's disease of bone. Calcif Tissue Int. 2008;83:414-24.

97. Visconti MR, Langston AL, Alonso N, Goodman K, Selby PL, Fraser WD, et al. Mutations of SQSTM1 are associated with severity and clinical outcome in Paget disease of bone. J Bone Miner Res. 2010;25:2368-73.

98. Selby PL, Davie MW, Ralston SH, Stone MD. Guidelines on the management of Paget's disease of bone. Bone. 2002;31:366-73.

99. Ralston $\mathrm{SH}$ Bisphosphonates in the management of Paget's disease. 2020; Bone 138:115465.

100. Joshua F, Epstein M, Major G. Bisphosphonate resistance in Paget's disease of bone. Arthritis Rheum. 2003;48:2321-3.

101. Rendina D, Mossetti G, Viceconti R, Sorrentino M, Nunziata V. Risedronate and pamidronate treatment in the clinical management of patients with severe Paget's disease of bone and acquired resistance to bisphosphonates. Calcif Tissue Int. 2004;75:189-96.

102. Papapoulos SE, Eekhoff EMW, Zwinderman AH. Acquired resistance to bisphosphonates in Paget's disease of bone. J Bone Miner Res. 2006;21:P88-91.

103. Lyles KW. What is "resistance" in Paget's disease of bone? Arthritis Rheum. 2003;48:2097-9.

Publisher's Note Springer Nature remains neutral with regard to jurisdictional claims in published maps and institutional affiliations. 